\title{
MORPHOPATHOLOGICAL CHARACTERISTICS OF HISTOMONIASIS IN JAPANESE QUAILS (COTURNIX COTURNIX JAPONICA)
}

\section{G. FARJANIKISH \& A. BEYRAGHI}

\begin{abstract}
Department of Pathobiology, School of Veterinary Medicine,
\end{abstract} Lorestan University, Khoramabad, Iran

\begin{abstract}
Summary
Farjanikish, G. \& A. Beyraghi, 2018. Morphopathological characteristics of histomoniasis in Japanese quails (Coturnix coturnix japonica). Bulg. J. Vet. Med., 21, No 1, 103-107.

Histomoniasis is a disease caused by a protozoan parasite belonging to the trichomonas group which is prevalent all over the world. Nine Japanese quails (Coturnix coturnix japonica) with history of depression, anorexia, ruffled feathers, lethargy and watery yellowish diarrhoea were referred to the clinic. The client claimed that 12 quails with similar signs died during the last 8 days and the other remaining quails were at risk. Postmortem examination revealed caseous exudate in the coelomic cavity, swollen liver with yellowish white nodules and distended caecum with multifocal, slightly elevated, yellow lesions in the wall. Microscopically, diffuse necrotising hepatitis and severe typhlitis associated with numerous intralesional Histomonas trophozoites, infiltrated inflammatory cells were observed. Degenerated trophozoites were also identified in the necrotic areas. These gross and microscopical features are characteristic of histomoniasis.
\end{abstract}

Key words: histomoniasis, histopathology, liver, caecum, quail

Histomoniasis is a disease caused by the protozoan parasite Histomonas meleagridis. It is often called blackhead disease, enterohepatitis and enzootic typhlohepatitis. H. meleagridis is belonging to the trichomonas group which is prevalent all over the world (McDougald, 2006).

Despite the limited number of confirmed reports, the parasite can affect gallinaceous (chicken-like) birds besides turkeys including chickens, grouse, pheasants, partridges, quails and pea-fowl. The turkeys suffer from the most serious expression of the illness. Histomoniasis in turkeys was first described in 1893 (Smith, 1995). The parasite lesions cause high morbidity and mortality and the disease affects the liver and caecum of domestic and wild birds, triggering degenerative and necrotising inflammation (Trindade et al., 2011). It is transmitted primarily by direct contact when birds ingest contaminated faeces or eggs from the helminth Heterakis gallinarum containing 
the protozoan (Sentier-Cue et al., 2009; Popp et al., 2011).

The eggs are highly resistant to environmental conditions, and $H$. meleagridis is, in turn, highly viable inside the eggs, even for years. Birds are infected once they ingest the eggs of the nematode in soil, or sometimes through earthworms which had ingested the egg-contaminated soil. Outbreaks can occur rapidly from the heavily infected bird in a flock through normal contact between uninfected and infected birds and their droppings in the total absence of caecal worms ( $\mathrm{Hu} \&$ McDougald, 2003). For this reason, infection can spread very quickly. Once inside the digestive system of the host, the protozoan is moved to the caecum along with the eggs of $H$. gallinarum (McDougald, 2006).

In this study we describe morphopathological characteristics of histomoniasis in quails. Nine Japanese quails (Coturnix coturnix japonica) with history of depression, anorexia, reduced feed consumption and decrease of body weight with progressive emaciation, standing or sitting with ruffled feathers, lethargy, watery yellowish diarrhoea and high mortality were referred to the clinic. The client claimed that during last 8 days, 12 quails with similar signs died and other remaining quails were at risk. All the chicks belonged to the same hatch of the same breeding stock at the age of 6-9 months. Quails were fed a commercial non-medicated, maize and soybean meal diet that met their nutrient requirements. Physical examinations of the affected quails showed emaciation and slightly swollen abdomen.

After postmortem observation, liver and caecum samples were taken and after fixation in $10 \%$ buffered formalin, were dehydrated in graded ethanol, cleared in xylene and embedded in paraffin wax.
Sections of $5 \mu \mathrm{m}$ thicknesses were stained by haematoxylin and eosin (H\&E) and studied microscopically. In most carcasses, caseous exudate was in the coelomic cavity. Grossly, the lesions were restricted to the liver and caecum. The liver of all quails had yellowish white nodules. The livers were enlarged (hepatomegally) with multifocal to coalescing nodules 1.0 to $2.5 \mathrm{~cm}$ in diameter, representing the area of necrosis which appeared as yellowish white (Fig. 1). The necrotic nodules showed a central depression surrounded by a red halo. The caecum was distended and had multifocal, slightly elevated, yellow transmural lesions wall. The mucosa contained multifocal yellow lesions containing friable caseous material. Adjacent to these mucosal lesions, the mucosa was reddened with irregular thickening.

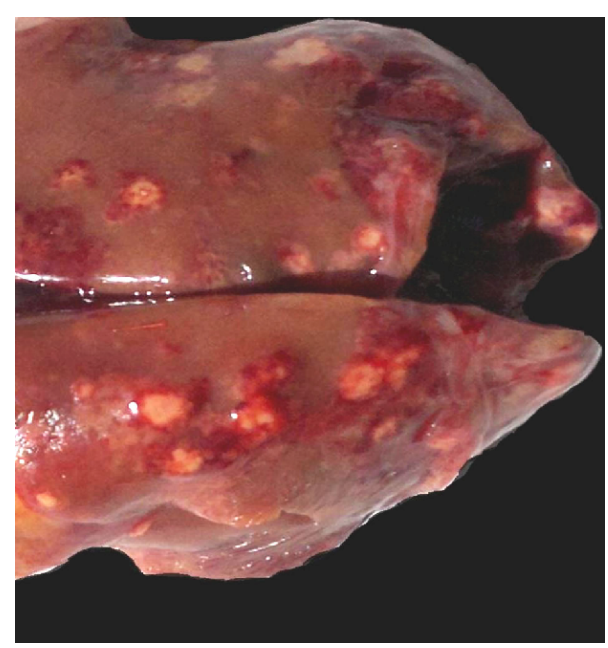

Fig. 1. Quail. Enlarged liver with multifocal to coalescing nodules measuring 1.0 to $2.5 \mathrm{~cm}$ in diameter, which represent the yellowish white area of necrosis.

Microscopically, diffuse necrotising hepatitis and severe typhlitis associated with thickening of the caecal wall due to 
numerous intralesional individual and clustered trophozoites (morphologically compatible with Histomonas meleagridis), infiltration of eosinophils, lymphocytes and macrophages into the wall were observed (Fig. 2). Degenerated trophozoites were also identified in the necrotic areas of the livers. Fatty change of the hepatocytes and congestion of sinusoids and fibrinoid necrosis of the vessels of the caecum were also observed (Fig. 3).
The quails were diagnosed with histomoniasis based on clinical signs, and primarily by the lesions restricted to the caecum and liver observed during the necropsy and confirmed by the histopathology findings.

Histomoniasis is frequently diagnosed in the United States, primarily in turkeys (Norton et al., 1999; Senties-Cue et al., 2009), domestic chickens (Cortes et al., 2004) and several wild bird species (Mc-

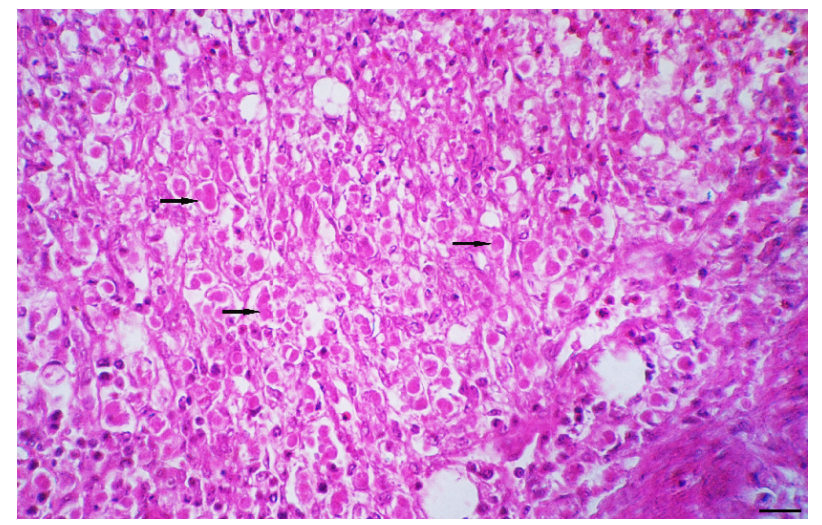

Fig. 2. Quail. Numerous intralesional individual and clustered Histomonas trophozoites (arrows) in the caecum $(\mathrm{H} \& \mathrm{E}$, bar $=25 \mu \mathrm{m})$.

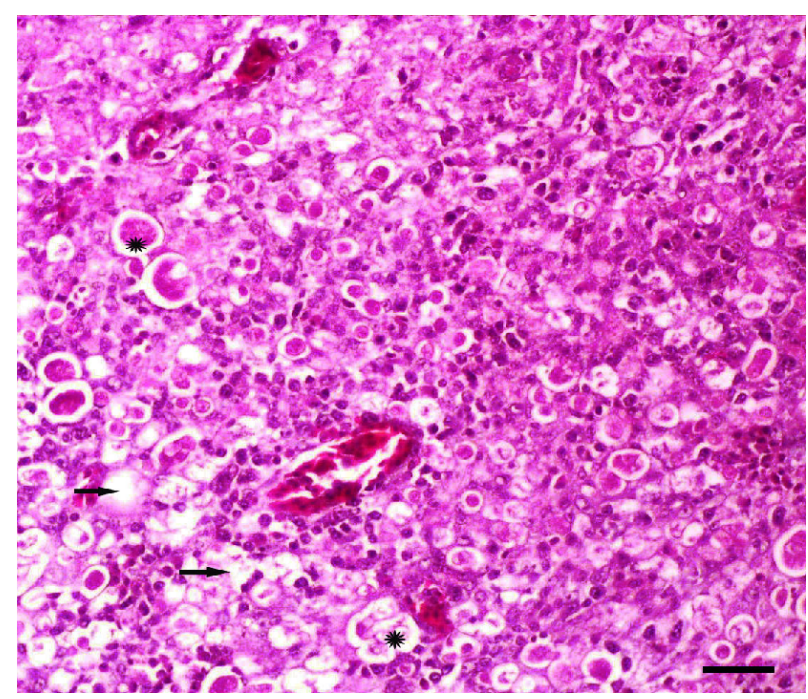

Fig. 3. Quail. Degenerated trophozoites (asterisk) in the necrotic areas of the livers with fatty change of the hepatocytes (arrows) ( $\mathrm{H} \& \mathrm{E}$, bar $=25 \mu \mathrm{m}$ ). 
Dougald et al., 2012). This disease can cause high mortality, particularly in turkey poults, but it can also affect older birds (Reis et al., 2009). The clinical signs include depression, reduced appetite, poor growth, increased thirst, sulphur-yellowish diarrhoea, listlessness and dry, ruffled feathers. The head may become cyanotic (McDougald, 2006). In this study, quails presented similar clinical signs with high mortality.

Although the gross lesions are usually compatible with the disease, it is important to confirm the diagnosis and rule out similarly appearing diseases such as salmonellosis and coccidiosis. This is especially important early in the progression of the disease. A diagnosis of histomoniasis can best be made upon examination of a fresh, refrigerated carcass. In this study, fresh dead quails were presented for examination and no worms were found in the gastrointestinal tract of necropsied quails but gross and histopathological examinations confirmed the histomoniasis. Similarly to our study, an outbreak of blackhead disease in farm-reared bobwhite quail (Colinus virginianus) was reported (McDougald et al., 2012).

Histomonads from the caecal lesions commonly gain entry to small veins and are carried by the blood to the liver. There, the histomonads continue reproducing and cause focal areas of necrosis and an intense inflammatory response. Unusual lesions have been observed in other organs of turkeys such as the cloacal bursa, lungs, and kidneys (Sentier-Cue et al., 2009). In the present study, the lesions were restricted to the caecum and liver. The caecum was distended and had multifocal, slightly elevated, yellow lesions on the serosa. Microscopically, diffuse necrotising hepatitis and severe typhlitis associated with numerous intralesional Histo- monas trophozoites, infiltrated lymphocytes and macrophages, was observed. At necropsy, the other internal organs were grossly normal and there were no specific macroscopic lesions in other organs.

Currently, prevention is the sole effective mode of treatment. Deworming of birds with anthelmintic can reduce exposure to the caecal nematodes that carry the protozoan. Good management of the farm, including immediate quarantine of infected birds and sanitation, is the main useful strategy for controlling the spread of the parasitic contamination (Hegngi et al., 1999; McDougald, 2008; Callait-Cardinal et al., 2009). The only drug used for the control (prophylaxis) in the USA is nitarsone at $0.01875 \%$ of feed until 5 days before marketing. Natustat and nitarsone were shown to be effective therapeutic drugs (Duffy et al., 2005). Nifurtimox, a compound with known antiprotozoan activity, was demonstrated to be significantly effective at 300-400 ppm, and well tolerated by turkeys (Hauck et al., 2010). Paromomycin is registered in the EU for treatment and prevention of the disease with better clinical response than preventive therapy (Bleyen et al., 2009; van der Heijden, 2009; Hafez et al., 2010).

In this study, we recommended to the owner to quarantine the infected birds and sanitation immediately, as the main useful strategy for controlling the spread of the parasitic contamination.

\section{REFERENCES}

Bleyen, N., K. De Gussem, A. D. Pham, E. Ons, N. Van Gerven \& B. M. Goddeeris, 2009. Non-curative, but prophylactic effects of paromomycin in Histomonas meleagridis-infected turkeys and its effect on performance in non-infected turkeys. $V e$ terinary Parasitology, 165, 248-255. 
Callait-Cardinal, M. P., E. Gilot-Fromont, L. Chossat, A. Gonthier, C. Chauve \& 1. Zenner, 2009. Flock management and histomoniasis in free-range turkeys in France: Description and search for potential risk factors. Epidemiology and Infections, 138, 353-363.

Cortes, P. L., R. P. Chin, M. C. Bland, R. Crespo \& H. L. Shivaprasad, 2004. Histomoniasis in the bursa of Fabricius of chickens. Avian Diseases, 48, 711-715.

Duffy, C. F., M. D. Sims \& R. F. Power, 2005. Evaluation of dietary Natustat for control of Histomonas meleagridis in male turkeys on infected litter. Avian Diseases, 49, 423-425.

Hafez, H. M., R. Hauck, W. Gad, K. De Gussem \& A. Lotfi, 2010. Pilot study on the efficacy of paromomycin as a histomonostatic feed additive in turkey poults experimentally infected with Histomonas meleagridis. Archives of Animal Nutrition, 64, 77-84

Hauck, R., A. L. Fuller, G. Greif \& L. R. McDougald, 2010. Evaluation of nifurtimox for potential use in control of histomoniasis in turkeys. Avian Diseases, 54, 28-32.

Hegngi, F. N., J. Doerr, T. S. Cummings, R. D. Schwartz, D. Saunders, A. Zajac, C. T. Larsen \& F. W. Pierson, 1999. The effectiveness of benzimidazole derivatives for the treatment and prevention of histomoniasis (blackhead) in turkeys. Veterinary Parasitology, 81, 29-37.

Hu, J. \& L. R. McDougald, 2003. Direct lateral transmission of Histomonas meleagridis in turkeys. Avian Diseases, 47, 489-492.

McDougald, L. R., 2006. Blackhead disease (Systemic histomoniasis) in poultry: A critical review. Avain Diseases, 49, 462-476.

McDougald, L. R., 2008. Histomoniasis (blackhead) and other protozoan diseases of the intestinal tract. In: Diseases of Poultry, $12^{\text {th }}$ ed, eds Y. M. Saif, A. M. Fadly, J. R. Glisson, L. R. McDougald, L. K. Nolan \& D. E. Swayne, Iowa State University Press, Ames, IA., pp. 1095-1100.
McDougald, L. R., M. Abraham \& R. B. Beckstead, 2012. An outbreak of blackhead disease (Histomonas meleagridis) in farm-reared bobwhite quail (Colinus virginianus). Avian Diseases, 56, 754-756.

Norton, R. A., F. D. Clark \& J. N. Beasley, 1999. An outbreak of histomoniasis in turkeys infected with a moderate level of $A s$ caridia dissimilis but no Heterakis gallinarum. Avian Diseases, 43, 342-348.

Popp, C., R. Hauck, B. Blazey, A, Hanel \& H. M. Hafez, 2011. An unusual outbreak of histomoniasis in a commercial turkey flock. Berliner und Münchener Tierärztliche Wochenschrift., 125, 153-158.

Reis, J. J, R. B. Beckstead, C. C. Brown \& R. W. Gerhold, 2009. Histomonas meleagridis and capillarid infection in a captive chukar (Alectoris chukar). Avian Diseases, 53, 45-46.

Sentier-Cue, G., R. P. Chin \& H. L. Shivaprasad, 2009. Systemic histomoniasis associated with high mortality and unusual lesions in the bursa of Fabricius and lungs in commercial turkeys. Avian Diseases, 53, 231-238.

Smith, T., 1995. An infectious disease among turkeys caused by protozoa (infectious enterohepatitis). USDA's Bureau of Animal Industry Bulletin, 8, 1-3.

Trindade, M. M., G. Scheneiders, I. O. Correa, M. Flores \& G. D. Kommers, 2011. Histomoníase em pavão (Pavo cristatus). A Hora Veterinária, 184, 56-58.

van der Heijden, H., 2009. Detection, typing and control of Histomonas meleagridis, $\mathrm{PhD}$ thesis, Utrecht, The Netherlands.

Paper received 10.03.2016; accepted for publication 08.04.2016

\section{Correspondence}

Ghasem Farjanikish, DVM, PhD

Assist. Prof. of Veterinary Pathology

Department of Pathobiology

School of Veterinary Medicine,

Lorestan University, Khoramabad, Iran, e-mail: farjanikish.gh@gmail.com 